\title{
Seasonal Compensation of Predation and Harvesting
}

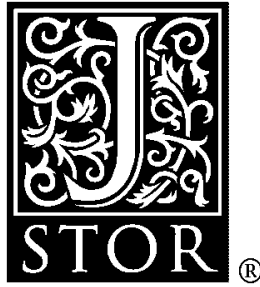

\author{
Mark S. Boyce; A. R. E. Sinclair; Gary C. White
}

Oikos, Vol. 87, No. 3. (Dec., 1999), pp. 419-426.

Stable URL:

http://links.jstor.org/sici?sici=0030-1299\%28199912\%2987\%3A3\%3C419\%3ASCOPAH\%3E2.0.CO\%3B2-A

Oikos is currently published by Nordic Society Oikos.

Your use of the JSTOR archive indicates your acceptance of JSTOR's Terms and Conditions of Use, available at

http://www.jstor.org/about/terms.html. JSTOR's Terms and Conditions of Use provides, in part, that unless you have obtained prior permission, you may not download an entire issue of a journal or multiple copies of articles, and you may use content in the JSTOR archive only for your personal, non-commercial use.

Please contact the publisher regarding any further use of this work. Publisher contact information may be obtained at http://www.jstor.org/journals/oikos.html.

Each copy of any part of a JSTOR transmission must contain the same copyright notice that appears on the screen or printed page of such transmission.

The JSTOR Archive is a trusted digital repository providing for long-term preservation and access to leading academic journals and scholarly literature from around the world. The Archive is supported by libraries, scholarly societies, publishers, and foundations. It is an initiative of JSTOR, a not-for-profit organization with a mission to help the scholarly community take advantage of advances in technology. For more information regarding JSTOR, please contact support@jstor.org. 


\title{
Seasonal compensation of predation and harvesting
}

\author{
Mark S. Boyce, A. R. E. Sinclair and Gary C. White
}

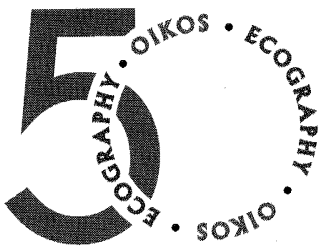

Boyce, M. S., Sinclair, A. R. E. and White, G. C. 1999. Seasonal compensation of predation and harvesting. - Oikos 87: 419-426.

\begin{abstract}
Compensatory mortality or natality can operate as a consequence of seasonally driven mechanisms of density dependence. Our objective is to clarify the relationship between compensation and density dependence in population models for vertebrates when seasonality is present. Field studies of a variety of species have demonstrated that due to compensation, predation or human harvest may not influence springbreeding or pre-harvest-season densities. Compensation seems to contradict most harvesting and predation models because these models predict that harvests or predation will always reduce equilibrium population size. In these population models sustainable harvests are attainable because of density dependence. The apparent discrepancy is attributable to the failure of most population models to incorporate the details of environmental seasonality. We review seasonally explicit models of population dynamics to illustrate how density dependence is the mechanism behind compensatory mortality and natality. Even though spring-breeding or pre-season densities can remain unaffected or even increased by harvesting, harvesting or predation generally reduces the integral of population size. Compensatory mortality and natality are often cited as the basis for sustainable harvests of wildlife populations.
\end{abstract}

M. S. Boyce, Dept of Biological Sciences, Univ. of Alberta, Edmonton, AB, Canada T6G 2E9 (boyce@ualberta.ca). - A. R. E. Sinclair, Centre for Biodiversity, Univ. of British Columbia, Vancouver, BC, Canada V6T 1Z4. - G. C. White, Dept of Fishery and Wildlife Biology, Colorado State Univ., Fort Collins, CO 80523, USA.

"many more individuals of each species are born than can possibly survive..." Darwin (1859)

\section{Introduction}

Darwin's. ideas on the principle of natural selection were predicated on the observation that there was an annual surplus in the seasonal dynamics of a population. This same premise also forms the basis for sustainable harvests of natural populations. Indeed, the foundation for wildlife management is that each year there is a "doomed surplus" of animals produced that will never survive the seasonal bottleneck (Errington 1945, Bartmann et al. 1992). Sustainable harvests are justified on the premise that this doomed surplus can be removed for human harvest without negatively affecting population size. Studies of many species including bobwhite (Colinus virginianus) (Errington 1945, Roseberry and Klimstra 1984), cottontail rabbits (Sylvilagus floridanus; Errington 1946), muskrats (Ondatra zibethicus; Clark 1987), willow grouse (Lagopus lagopus; Smith and Willebrand 1999), ruffed grouse (Bonasa umbellus; Small et al. 1991), and mountain goats (Oreamnos americanus; Swenson 1985) show that hunting has little effect on densities at certain succeeding seasons of the year, i.e., spring-breeding or pre-huntingseason densities.

A similar argument has been made in favour of predator protection, i.e., predators remove the "doomed surplus" and they need not have any consequences to population size (Errington 1971). Likewise,

This is an invited Minireview on the occasion of the 50th anniversary of the Nordic Ecological Society Oikos.

Copyright (C) OIKOS 1999

ISSN 0030-1299

Printed in Ireland - all rights reserved 
Côté and Sutherland (1997) concluded that predator control has no consequence to spring-breeding densities of birds. Yet, like heavy human harvest, predators can have consequences for prey abundance thereby justifying hunting restrictions and predator control (Ellison 1991, Gasaway et al. 1992).

The principles of compensation would appear to fly in the face of predictions of models of harvesting and predation (Begon et al. 1986, Sinclair and Pech 1996) where any harvest or predation results in a reduction in equilibrium population size (Silliman and Gutsell 1958, Caughley 1977). Based on simple population models like the logistic, the assumption is that as the population is reduced below carrying capacity, a surplus of young will be produced beyond the number needed to sustain the population at that level (Ricker 1958, Peek 1986). The reason for the apparent contradiction is the fact that most population models ignore the details of annual seasonality. Seasonality can complicate the dynamics of population models and can yield dynamical behaviours that may not emerge from models that do not incorporate seasonality (Kot and Schaffer 1984, Batzli 1999, Jonzén and Lundberg 1999). We explain how seasonality in density dependence is one mechanism that underlies compensatory mortality and natality. Further we show how low to moderate harvests or predation actually can increase survival and breeding population size.

\section{Compensation}

Compensation is the demographic response to predation or harvest mortality. Compensation is usually due to density dependence, e.g., we might see a decrease in natural mortality in response to the reduction in population size caused by predation or harvest. This is called compensatory mortality. Alternatively increased availability of food for survivors of harvest or predation can result in an increase in reproductive output, i.e., compensatory natality.

Field studies of a number of species have demonstrated compensatory mortality and/or compensatory natality in response to harvest or predation (Staines 1978, McCullough 1979, Burnham and Anderson 1984, Peek 1986, Bartmann et al. 1992, Nichols 1991, White and Bartmann 1998). The ramifications are that spring-breeding densities may be unaffected by variation in hunter harvest or predation (Errington 1945, Newton 1993) and that it is not possible to stockpile populations for future hunting seasons (Anderson and Burnham 1976). We envisage that compensatory mortality and natality usually operate through density dependence within the year.

Compensatory mortality has received considerable attention by waterfowl biologists (Anderson and Burnham 1976, Nichols et al. 1984, Kokko et al. 1998), and experimental study in cervids (Bartmann et al. 1992,
Gaillard et al. 1998, White and Bartmann 1998). A variety of statistical approaches have been used to detect compensation, depending on the available data (Nichols 1991, Smith et al. 1992). Repeated analysis with a number of populations give weight of evidence for the importance of compensation (Williams 1997). Although these analyses offer important insight into the process of compensation, only recently has anyone proposed how such analyses fit into an actual population model from which one could examine ramifications for population dynamics (Jonzén and Lundberg 1999).

Compensatory natality also has been documented in a variety of species. Swenson (1985) found that recruitment rates for populations of Rocky Mountain goats (Oreamnos americanus) were higher after hunting had reduced the number of goats during the previous fall. Harvesting reduced competition for winter forage permitting increased production of kids. Similarly, there is good evidence of density-dependent reproductive rates in wood ducks (Aix sponsa; Haramis and Thompson 1985, Nichols 1991). Errington (1945) offered bobwhite as a species for which compensatory mortality resulted in invariant spring-breeding densities. More extensive examination by Roseberry and Klimstra (1984), however, revealed that compensatory natality was also operative such that pre-hunting-season populations of bobwhite were relatively constant, irrespective of hunter harvests.

\section{Harvesting and predation models}

A common view based on simplistic harvesting models is that population size must be reduced below the carrying capacity to generate a croppable surplus (Caughley 1977: 277). Several such harvesting models have been developed for fisheries (Schaefer 1954, Gulland 1961, Fox 1970) - all such models rely on density dependence for optimization (Mendelssohn 1976). Harvesting reduces population size and increases recruitment, with recruitment being the result of changes in either natality and mortality processes or both. Typical form of such models is illustrated by an extension of the logistic:

$\mathrm{d} N / \mathrm{d} t=r N(1-N / K)-h N$,

where $N$ is population size, $r$ is the potential growth rate, $K$ is the carrying capacity or the equilibrium population size where $\mathrm{d} N / \mathrm{d} t=0$ with no harvesting, and $h$ is the per capita harvest rate. (We will not consider more complex fisheries models such as cohort analyses which assume density-dependent juvenile survival [Gulland 1977].)

One way to illustrate this sort of harvesting model is to plot the population growth rate as a function of stock size (Fig. 1). A message from this model is that harvest always reduces equilibrium population size unless one 


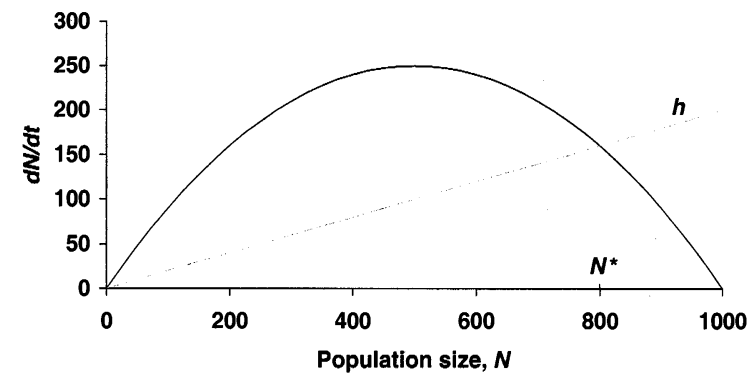

Fig. 1. Population dynamics model with harvesting proportional to the population size with the logistic model (see eq. 1). Equilibrium population size, $N^{*}$, occurs where the population's growth curve and the harvesting line intersect.

can somehow alter the density-dependent function (Sinclair and Pech 1996).

The same model structure has been used to model the influence of predation. For example, Yodzis (1989) writes

$\mathrm{d} N / \mathrm{d} t=r N(1-N / K)-P F(N)$,

where $P$ is the number of predators and $F(N)$ is a functional response. Graphically this yields a model essentially the same as for the harvesting model except for the flexible shape of the functional response (Fig. 2). Again, one of the conclusions from this model is that any predation will always result in an equilibrium population size that is lower than if predation were absent.

Murray (1979) proposed another approach, where he plotted birth and death rates as a function of population size, but again ignored the seasonal details of births and deaths. As the population becomes larger, generally we expect to see the death rate increase and the birth rate decline until births equal deaths and the population achieves equilibrium density. Using this approach, one might model either predation or harvest as an across-theboard increase in mortality rate resulting in a reduced equilibrium density (Fig. 3).

Note that in each of these models, we cannot find a plausible solution invoking compensatory mortality (Sinclair and Pech 1996). Any exploitation of an animal

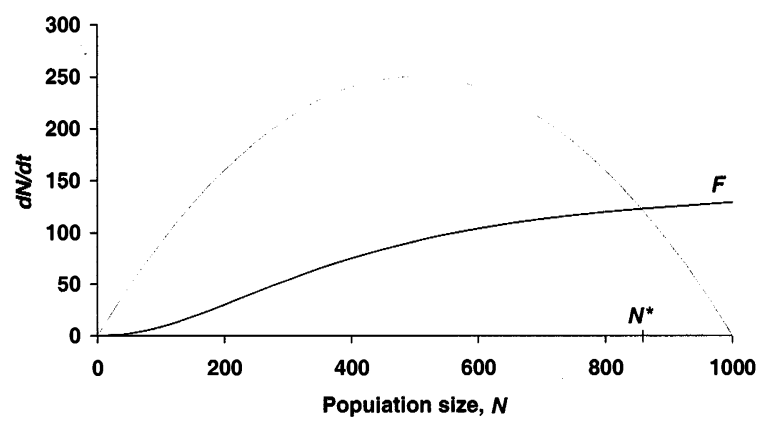

Fig. 2. Prey dynamics under logistic functional response as per eq. 2. Equilibrium prey population size occurs at $N^{*}$, where the prey's growth curve and the functional response curve intersect.

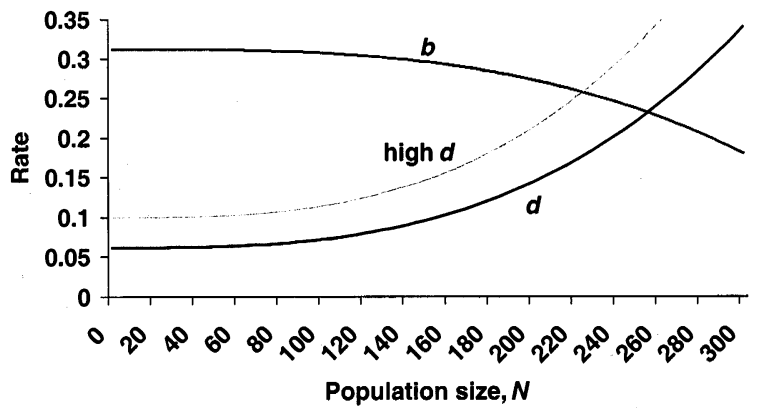

Fig. 3. Density-dependent population growth as a function of birth $(b)$ and death $(d)$ rates. Where the $b$ and $d$ curves intersect is equilibrium, $N^{*}$. Increasing death rate by harvesting or predation to "high $d$ " results in a decrease in $N^{*}$.

population is seen to reduce its abundance (Silliman and Gutsell 1958). Seasonality is usually ignored in such models.

\section{Biological mechanisms}

The biological mechanisms by which density dependence occurs certainly shape the opportunity for compensation to function. The usual conceptualization of compensation is a consequence of resource limitation, e.g., food. But other possibilities include density-dependent predation, cannibalism, parasitism, disease, or density-dependent dispersal. Regulation may be seasonal, e.g., research on black-headed gulls (Larus ridibundus) suggested that density dependence occurred on wintering areas (Lebreton 1981). Likewise, in many temperate and arctic ungulate populations we find that winter ranges are limited and density-dependent food limitation on wintering grounds may determine carrying capacity (Connolly 1981). But the particular timing of density dependence appears to vary among species (Morris 1996).

In Fig. 4 we present a hypothetical annual cycle showing how a population without harvest maintains higher numbers longer but ultimately declines to the

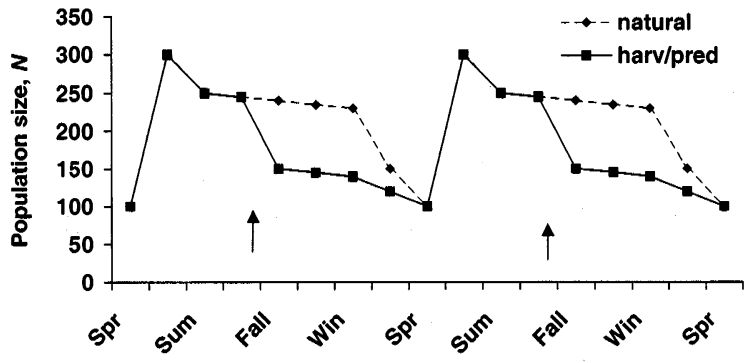

Fig. 4. Annual cycle for two populations: one with a seasonal cull indicated by arrows, the other with natural mortality. Spring-breeding densities are identical for both populations due to compensation during the winter season. 


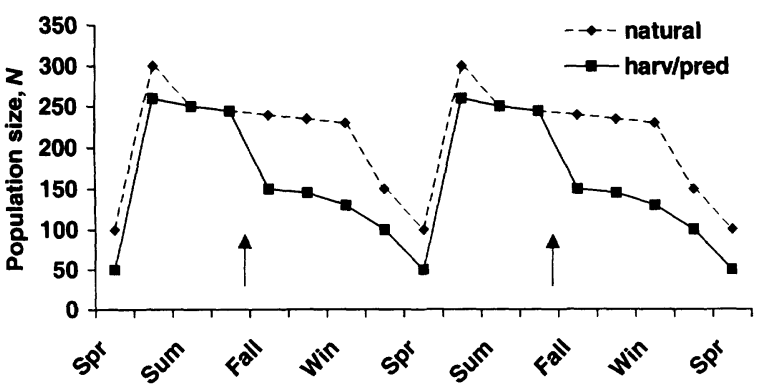

Fig. 5. Annual cycle for two populations: one with a seasonal cull indicated by arrows, the other natural with no harvest. In this case both compensatory mortality and natality function to yield identical pre-harvest densities for each.

same spring-breeding density (see Newton 1998). An important point to note is that the integral (average) of population size over the course of the year is considerably lower in the harvested population, and this seasonally reduced density is what creates the densitydependent response that results in compensatory mortality. An alternative scenario is sketched for a species with compensatory natality in which pre-season densities are constant, as in bobwhite (Fig. 5). Again, note that the integral over the year for the unharvested population is substantially higher than for the harvested population.

One of the better examples of a population exhibiting a "doomed surplus" is work with red grouse (Lagopus lagopus scotticus) in eastern Scotland (Jenkins et al. 1964). Red grouse establish territories in the autumn, but there are more birds than territories on the heather moorland. Tagging studies of both territorial and nonterritorial birds revealed that nearly all of the mortality occurred amongst nonterritorial grouse. When a territory holder died, its place was taken quickly by a nonterritorial bird so that the density on territories was held steady until the spring breeding season. Predators essentially removed the nonterritorial surplus or created opportunities for the nonterritory holders to become territory holders.

The red grouse example matches nicely with Errington's $(1945,1946)$ notion of a "doomed surplus" based on his field observations of bobwhite, cottontail rabbits, and muskrats. In early work with bobwhite, Errington and Hamerstrom (1936) found that birds in habitats with poor cover experienced higher rates of predation than those in areas with good cover. This led them to conclude that lack of cover was the ultimate cause of death. Populations above the capacity of the land were "doomed" to suffer higher rates of predation, disease, or starvation. Even though predation or harvest may be substantial, for fecund species like bobwhites, cottontails, and muskrats, there may be no consequence for the breeding density.

Compensation also can occur in response to limited food resources, independent of cover. A study of wood pigeons (Columba palumbus) in Britain illustrates how regulation by food resources can result in increased spring-breeding densities in harvested populations (Murton et al. 1974). Wood pigeons depleted food resources during the course of the winter so that by late winter in unharvested populations mortality rates were very high. When hunting reduced density, each individual had sufficient food to ensure survival during the course of the winter such that most of the wood pigeons that survived hunting, also survived the winter. Indeed, the competitive depletion of food was so high without exploitation that the spring-breeding densities actually were higher in the hunted population (Murton et al. 1974).

The details of demographic response under compensation vary substantially among species and even among populations of the same species (Fretwell 1972). Many species show a compensatory response in juvenile mortality (Gaillard et al. 1998). Harvest or predation mortality may influence adults as well as juveniles, but the first demographic response is usually a reduction in mortality of prereproductives (Eberhardt 1977). Examples include beavers (Castor canadensis; Boyce 1981) and muskrats (Clark 1987). Fowler (1987) has compiled a catalogue of density-dependent responses by mammals.

Dispersal is fundamental to compensation in several species. Harvests of willow grouse (Smith and Willebrand 1999) and ruffed grouse (Bonasa umbellus; Small et al. 1991) are compensated by birds moving in from surrounding areas after harvest. Frequently a population of floaters or surplus animals without territories exist that will take up territories when harvest or predation removes animals. Newton (1992) reviewed 54 experimental removals of songbirds, grouse, waders, and raptors finding that in 41 of these studies removed birds were quickly replaced by others from a nonterritorial contingent, so that breeding density was maintained.

In some species, detection of compensatory responses can be difficult to detect even in experimental studies because of enormous variation from year to year. For example, density-dependent survival is expressed during severe winters in mule deer (Odocoileus hemionus) (Bartmann et al. 1992, Unsworth et al. 1999). During mild winters no compensation is detectable, but longterm population sizes are established by what happens during severe winters. Similarly, survival of juvenile African buffalo (Syncerus cafer) varied with rainfall making detection of density dependence difficult among young-aged animals (Sinclair 1977).

\section{Seasonally explicit models}

One obvious difference between the models described in III and the biological processes described in IV is the 
lack of seasonality in the models. Indeed, compensatory mortality can be reconciled in harvesting models by incorporating seasonality. Two approaches are usually taken for modelling seasonality. One approach is to use continuous-time models with seasonal forcing functions (e.g., Boyce and Daley 1980). We note that mortality is usually a continuous-time process whereas reproduction often occurs during a discrete breeding season, although the reproductive rate may depend on conditions prior to the reproductive season (Boyce and Tate 1982, Albon et al. 1983). An alternative approach is to use difference equations in discrete time (Kot and Schaffer 1984, Åström et al. 1996). To demonstrate how seasonality can result in compensation, we will use a discretetime approach.

\section{V.1. Seasonally explicit discrete-time survival}

We break the year into two seasons: a harvest season when mortality occurs at rate $h$, and the remainder of the year with a natural mortality rate of $m$. Then, annual survival is modelled by

$S=(1-h)(1-m)$.

If we replace $m$ with a density-dependent mortality function where mortality depends on the number of animals alive at the beginning of the natural mortality period, we obtain

$S=(1-h)\left\{1-\left[b_{0}+b_{1}(N-h N)\right]\right\}$,

where $N$ is pre-harvest population size, $b_{0}$ is the mortality rate when $(N-h N)$ is 0 , and $b_{1}$ is the slope of the linear density-dependent natural mortality function. We will not concern ourselves with the details of what happens within each time period, so we might imagine that the density at the beginning of the non-harvest season determines over winter mortality.

The model is quadratic with respect to $h$, yielding maximum survival at an intermediate harvest level. We find a maximum at

$h=\left(2 N b_{1}+\left[b_{0}-1\right]\right) / 2 N b_{1}$

with the remarkable result that a low to moderate harvest rate actually can increase the survival rate (Fig. 6). This result is not dependent on the linearity of the density-dependent function. Various nonlinear functions can yield qualitatively similar results. In fact, in many populations density dependence is strongest as the population approaches $K$ (Fowler 1987), as seen, for example, in wildebeest, Connochaetes taurinus (Mduma et al. 1999), which can amplify compensation (Fig. 7). Mathematically we obtain these results because of the interaction between the function of harvest and the reduced population during the non-harvest season.

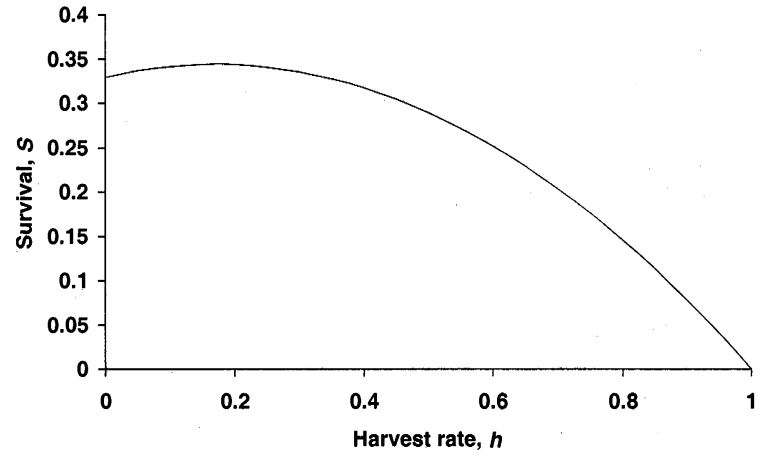

Fig. 6. Annual probability of survival as a function of harvest rate with linear density dependence as in eq. 4 with $N=90$, $b_{0}=0.17$, and $b_{1}=0.00556$. Note that survival actually is higher at low levels of harvest.

\section{V.2. Discrete-time population models}

Seasonality can be built into a difference equation population model by setting a different carrying capacity in good and bad seasons (Lebreton and Clobert 1991), analogous to the approach of seasonal forcing in continuous time models (Boyce and Daley 1980). An alternative approach is to expand upon the survival model that we presented in the previous section. For example, we can have a harvest season, followed by a birthing season, and finally an annual bottleneck. Again, all of the mortality in each of these seasons is discrete. Jonzén and Lundberg (1999) have proposed

$$
\begin{aligned}
N(t+1)= & N(t)[1-h][1+\beta-a N(t)(1-h)] \\
& \times[1-\alpha-c \Gamma],
\end{aligned}
$$

where $\Gamma=N(t)[1-h][1+\beta-a N(t)(1-h)]$. Here $\beta$ is the maximum per capita birth rate, $\alpha$ is the minimum per capita death rate, and $a$ and $c$ measure the strength of density dependence in the birth and death functions.

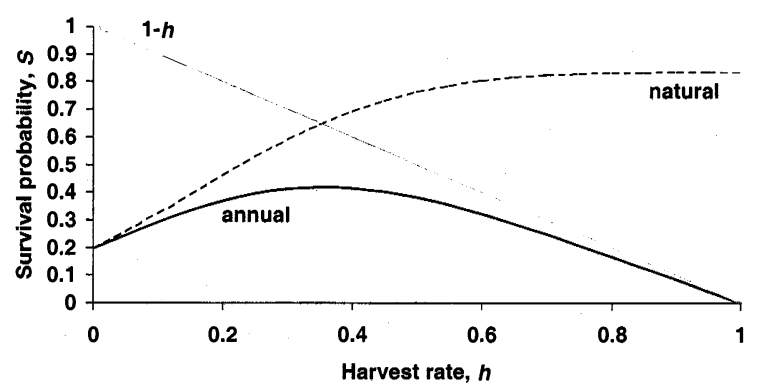

Fig. 7. Annual survival, $S$, as a function of harvest rate with nonlinear density dependence. Here we plot the components of the model: survival through the harvest season $(1-h)$ and natural survival during the remainder of the year. Nonlinearity amplifies the effect of compensation creating highest survival rates in populations with low to moderate levels of harvest or predation. 
This model yields the result that low to moderate levels of harvest create a compensatory effect that can increase average population size, parallel to the increased survival observed with the model in the previous section. In addition, Jonzén and Lundberg (1999) note that harvesting tends to stabilize population dynamics. The order of harvesting relative to the birthing season and the mortality season can alter the dynamics, pointing to the crucial determination of the optimum timing of harvest (Kokko and Lindström 1998, Kokko et al. 1998). Clearly the density-dependent processes operating in the population, whether they be during the birthing or mortality season, must occur after the harvest season for compensation to be realized.

Jonzén and Lundberg (1999) use the term overcompensation for the increase in population size that occurs with low to moderate harvest. Although this may be appropriate terminology, we caution that overcompensation is commonly used to describe the emergence of nonlinear dynamics in discrete-time models. The interaction between harvest and density dependence that creates increased survival or increased population size occurs under stable population dynamics.

\section{V.3. Trophic-level interactions}

Caughley (1976) emphasized that single-species models were inadequate for characterizing the dynamics emerging from trophic-level interactions. Similarly, rationale for harvesting is often placed in the context of the effects that unharvested populations can have on their food resources (Robinette et al. 1977). Seasonal food depletion, as in Murton et al.'s (1974) wood pigeon study, can be modelled explicitly to illustrate the mechanism by which harvested populations might achieve higher spring-breeding densities than unharvested populations.

To illustrate, we will assume that food resources at the end of a brief growing season are equally abundant for a hunted and an unhunted population. For simplicity we will assume that these food resources, $f$, at time $i$ are depleted only by our target species such that

$f(i+1)=f(i)-N(i) \cdot c$,

where $c$ is the per capita consumption rate, monitored at monthly intervals, $i=1,2, \ldots$ We assume that the mortality rate is a convex function of food abundance, for example,

$m(i)=1-\left(1-\mathrm{e}^{-z \cdot f(i)}\right)$,

where $z$ is a constant that characterizes the decline in $m$ with increasing $f$. Then we can iterate the number of animals surviving through the course of the annual cycle for a harvested and an unharvested population. Results of such an exercise show that indeed, spring-

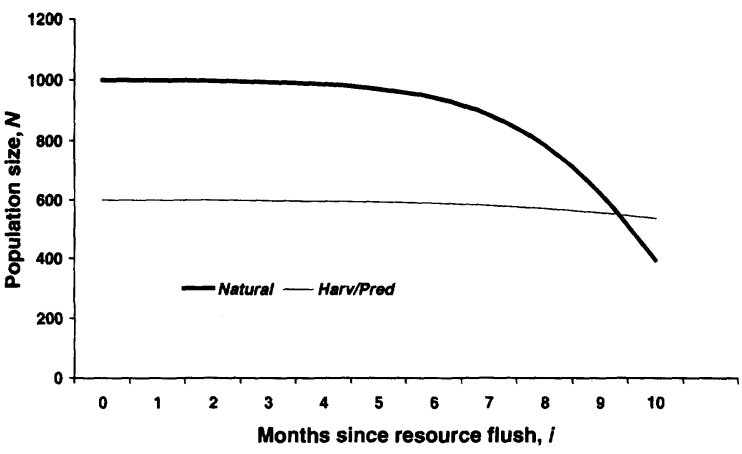

Fig. 8. Seasonal declines in population size for a population with no harvest (or predation) and another where densities were reduced by harvest or predation just after a pulse in food resources. Note that spring breeding densities are highest in the harvested population.

breeding densities can be higher in a harvested population (Fig. 8). Note that this model is analogous to the model of eq. 4 , except that density dependence based on population size is replaced by density dependence based on food supply.

\section{Conclusions}

Although Anderson and Burnham (1976) demonstrated compensatory mortality in a continuous-time model without seasonality, compensatory mortality usually occurs in a seasonal context. Absence of seasonality from the population model presented by Sinclair and Pech (1996) is why they concluded that compensation is unlikely. We believe that the primary mechanism for compensation is via density-dependent processes appearing at various times of the year.

Sinclair and Pech (1996: 169) assert that "where food or other resources are density-dependent, hunting, accidental deaths (e.g., road kills) or other non-density dependent mortalities will always result in a drop in the equilibrium population". This statement appears to contradict the notion of compensation, and indeed, it is not always true for equilibrium density at a certain time of the year, e.g., spring-breeding density. Yet, we believe that it is true for integral density throughout the year. This does not contradict the concept of compensation because it is indeed the density-dependent responses of compensatory mortality or compensatory natality at certain times of the year that allow for compensation.

With seasonality, density dependence after predation or harvest can actually increase seasonal abundance or increase annual survival, resulting in compensatory mortality. This occurs through the interaction between reduction in population size and the density-dependent response. A variety of mechanisms can yield this result. For example, high population density in an unexploited population can result in the depletion of food resources 
so that mortality can be high by the end of winter, whereas most remaining individuals may survive winter if numbers were reduced during autumn. Similarly, selective predation may suppress epizootics, e.g., red grouse killed by predators have more parasites (Hudson 1992).

We caution, however, that compensation does not always occur even when density dependence is present. For example, even though density dependence has been documented in grizzly bear (Ursus arctos) populations (Shaffer 1983, Boyce 1999), compensation may not occur because when a male bear is removed the replacing male is likely to kill the cubs of females within its home range (Swenson et al. 1997). Compensatory mortality is less likely to occur in species with high survival rates in the absence of hunting (Nichols 1991). Mechanisms of population regulation and thereby compensation are known to vary among habitats for populations of the same species (Fretwell 1972).

Compensation is fundamental as a principle in wildlife management (Nichols 1991, Bartmann et ar. 1992). We acknowledge that we do not fully understand the consequences of predation or harvesting in natural systems (Hilborn et al. 1995, Struhsaker 1998). But based on the abundant successes at achieving sustainable harvests of a large number of wildlife species (Geist and McTaggart-Cowan 1995, Medellín 1999), we have little doubt that sustainability is possible in ecological systems.

Acknowledgements - We thank Per Lundberg for providing information about his unpublished papers, Tom Fenchel for comments, and Jim Nichols for discussion. MSB was supported by the Vallier Foundation and a Wisconsin Distinguished Professorship at the University of Wisconsin and by an Erskine Fellowship at Canterbury University.

\section{References}

Albon, S. D., Mitchell, B. and Staines, B. W. 1983. Fertility and body weight in female red deer: a density-dependent relationship. - J. Anim. Ecol. 52: 969-980.

Anderson, D. R. and Burnham, K. P. 1976. Population ecology of the mallard. VI. The effect of exploitation on survival. - US Fish Wildl. Serv. Resource Publ. 128: 1-66.

Åström, M., Lundberg, P. and Lundberg, S. 1996. Population dynamics with sequential density dependencies. - Oikos 75: $174-181$.

Bartmann, R. M., White G. C. and Carpenter L. H. 1992. Compensatory mortality in a Colorado mule deer population. - Wildl. Monogr. 121.

Batzli, G. O. 1999. Can seasonal changes in density dependence drive population cycles? - Trends Ecol. Evol. 14: 129-131.

Begon, M., Harper, J. L. and Townsend, C. R. 1986. Ecology. - Blackwell Scientific, Oxford.

Boyce, M. S. 1981. Beaver life history responses to exploitation. - J. Appl. Ecol. 18: 749-753.

Boyce, M. S. 1999. Population viability for grizzly bears: a critical review. - Ursus Monogr. 5 (in press)

Boyce, M. S. and Daley, D. J. 1980. Population tracking of fluctuating environments and natural selection for tracking ability. - Am. Nat. 115: 480-491.
Boyce, M. S. and Tate, Jr., J. 1982. Pronghorn (Antilocapra americana) demography and hunting quotas in the Powder River Basin, Wyoming. - Proc. Int. Congr. Game Biol. 14: $101-106$.

Burnham, K. P. and Anderson, D. R. 1984. Tests of compensatory vs. additive hypothesis of mortality in mallards. Ecology 65: 105-112.

Caughley, G. 1976. Wildlife management and the dynamics of ungulate populations. - In: Coaker, T. H. (ed.), Applied biology, I. Academic Press, New York, pp. 183-246.

Caughley, G. 1977. Analysis of vertebrate populations. Wiley, New York.

Clark, W. R. 1987. Effects of harvest on annual survival of muskrats. - J. Wildl. Manage. 51: 265-272.

Connolly, G. E. 1981. Limiting factors and population regulation. - In: Wallmo, O. C. (ed.), Mule and black-tailed deer of North America. Univ. Nebraska Press, Lincoln, NE, pp. 245-285.

Côté, I. M. and Sutherland, W. J. 1997. The effectiveness of removing predators to protect bird populations. - Conserv. Biol. 11: 395-405.

Darwin, C. R. 1859. The origin of species by means of natural selection, or the preservation of favoured races in the struggle for life. - John Murray, London.

Eberhardt, L. L. 1977. Optimal management policies for marine mammals. - Wildl. Soc. Bull. 5: 162-169.

Ellison, L. N. 1991. Shooting and compensatory mortality in tetraonids. - Ornis Scand. 22: 229-240.

Errington, P. L. 1945. Some contributions of a fifteen-year study of the northern bobwhite to a knowledge of population phenomena. - Ecol. Monogr. 15: 1-34.

Errington, P. L. 1946. Predation and vertebrate populations. Q. Rev. Biol. 21: 144-177, 221-245.

Errington, P. L. 1971. Of predation and life. - Iowa State Univ. Press, Ames, IA.

Errington, P. L. and Hamerstrom, F. N. 1936. The Northern Bobwhite's winter territory. - Iowa State Coll. Agric. Res. Bull. 201: 305-443.

Fowler, C. 1987. A review of density dependence in populations of large mammals. - Curr. Mammal. 1: 401-441.

Fox, W. W. 1970. An exponential surplus yield model for optimizing exploited fish populations. - Trans. Am. Fish. Soc. 99: 80-88.

Fretwell, S. D. 1972. Populations in a seasonal environment. Princeton Univ. Press, Princeton, NJ.

Gaillard, J.-M., Festa-Bianchet, M. and Yoccoz, N. G. 1998. Population dynamics of large herbivores: variable recruitment with constant adult survival. - Trends Ecol. Evol. 13: $58-63$.

Gasaway, W. C., Boertje, R. D., Grangaard, D. V. et al. 1992. The role of predation in limiting moose at low densities in Alaska and Yukon and implications for conservation. Wildl. Monogr. 120: 1-59.

Geist, V. and McTaggart-Cowan, I. 1995. Wildlife conservation policy. - Detselig Enterprises, Calgary.

Gulland, J. A. 1961. Fishing and the stocks of fish at Iceland. - Fish. Invest. Lond. Ser. 2, 23(4): 1-52.

Gulland, J. A. 1977. Fish population dynamics. - Wiley, New York.

Haramis, G. M. and Thompson, D. Q. 1985. Density-production characteristics of box-nesting wood ducks in a northern greenhouse impoundment. - J. Wildl. Manage. 49: 429-436.

Hilborn, R., Ludwig, D. and Walters, C. J. 1995. Sustainable exploitation of renewable resources. - Annu. Rev. Ecol. Syst. 26: 45-67.

Hudson, P. 1992. Grouse in space and time. - Game Conservancy, Fordingbridge, Hants., UK.

Jenkins, D., Watson, A. and Miller, G. R. 1964. Predation and Red Grouse populations. - J. Appl. Ecol. 1: 183-195.

Jonzén, N. and Lundberg, P. 1999. Temporally structured density dependence and population management. - Ann. Zool. Fenn. 36: 39-44. 
Kokko, H. and Lindström, J. 1998. Seasonal density dependence, timing of mortality, and sustainable harvesting. Ecol. Model. 110: 293-304.

Kokko, H., Pöysä, H., Lindström, J. and Ranta, E. 1998. Assessing the impact of spring hunting on waterfowl populations. - Ann. Zool. Fenn. 35: 195-204.

Kot, M. and Schaffer, W. M. 1984. The effects of seasonality on discrete models of population growth. - Theor. Popul. Biol. 26: 340-360.

Lebreton, J.-D. 1981. Contribution à la dynamique des populations d'oiseaux. Modèles mathématiques en temps discret. - Ph.D. thesis, Université Lyon I, Lyon.

Lebreton, J.-D. and Clobert, J. 1991. Bird population dynamics, management, and conservation: the role of mathematical modelling. - In: Perrins, C. M., Lebreton, J.-D. and Hirons, G. J. M. (eds), Bird population studies: relevance to conservation and management. Oxford Univ. Press, Oxford, pp. 105-125.

McCullough, D. R. 1979. The George Reserve deer herd. Univ. Michigan Press, Ann Arbor, MI.

Mduma, S. A. R., Sinclair, A. R. E. and Hilborn, R. 1999. Food regulates the Serengeti wildebeest: a forty-year record. - J. Anim. Ecol. 68: 1101-1122.

Medellín, R. A. 1999. Sustainable harvest for conservation. Conserv. Biol. 13: 225

Mendelssohn, R. 1976. Optimization problems associated with a Leslie matrix. - Am. Nat. 110: 339-349.

Morris, D. W. 1996. Temporal and spatial population dynamics among patches connected by habitat selection. - Oikos 75: $207-219$

Murray, B. 1979. Population dynamics: alternative models. Academic Press, New York.

Murton, R. K., Westwood, N. J. and Isaacson, A. J. 1974. A study of wood-pigeon shooting: the exploitation of a natural animal population. - J. Appl. Ecol. 11: 61-81.

Newton, I. 1992. Experiments on the limitation of bird numbers by territorial behavior. - Biol. Rev. 67: 129-173.

Newton, I. 1993. Predation and limitation of bird numbers. Curr. Ornithol. 11: 143-198.

Newton, I. 1998. Population limitation in birds. - Academic Press, New York

Nichols, J. D. 1991. Responses of North American duck populations to exploitation. - In: Perrins, C. M., Lebreton, J.-D. and Hirons, G. J. M. (eds), Bird population studies: relevance to conservation and management. Oxford Univ. Press, Oxford, pp. 498-525.

Nichols, J. D., Conroy, M. J., Anderson, D. R. and Burnham, K. P. 1984. Compensatory mortality in waterfowl populations: a review of the evidence and implications for research and management. - Trans. N. Am. Wildl. Nat. Resour. Conf. 49: 535-554.

Peek, J. M. 1986. A review of wildlife management. - Prentice-Hall, Englewood Cliffs, NJ.

Ricker, W. 1958. Handbook of computations for biological statistics of fish populations. - Fish. Res. Bd. Can. Bull. 119.
Robinette, W. L., Hancock, N. V. and Jones, D. A. 1977. The Oak Creek mule deer herd in Utah. - Resource Publ. 77-15, Utah Div. Wildl., Salt Lake City, UT.

Roseberry, J. L. and Klimstra, W. D. 1984. Population ecology of the bobwhite. - Southern Illinois Univ. Press, Carbondale, IL.

Schaefer, M. B. 1954. Some aspects of the dynamics of populations important to the management of commercial marine fisheries. - Inter-Am. Trop. Tuna Comm. Bull. 1 (2): 26-56.

Shaffer, M. L. 1983. Determining minimum viable population sizes for the grizzly bear. - Int. Conf. Bear Res. Manage. 5: $133-139$.

Silliman, R. P. and Gutsell, J. S. 1958. Experimental exploitation of fish populations. - USDI Fish and Wildlife Serv., Fish Bull. 58(133): 214-252.

Sinclair, A. R. E. 1977. The African buffalo. - Univ. Chicago Press, Chicago.

Sinclair, A. R. E. and Pech, R. P. 1996. Density dependence, stochasticity, compensation and predator regulation. Oikos 75: 164-173.

Small, R. J., Holzwart, J. C. and Rusch, D. H. 1991. Predation and hunting mortality of ruffed grouse in central Wisconsin. - J. Wildl. Manage. 55: 512-520.

Smith, A. and Willebrand, T. 1999. Mortality causes and survival rates of hunted and unhunted willow grouse. - J. Wildl. Manage. 63: 722-730.

Smith, D. R., Diefenbach, D. R. and Conroy, M. J. 1992. Effect of density-dependent harvest rates on inferences about compensatory mortality. - In: McCullough, D. R. and Barrett, R. H. (eds), Wildlife 2001: populations. Elsevier, London, pp. 676-686.

Staines, B. W. 1978. The dynamics and performance of a declining population of red deer (Cervus elaphus). - $\mathbf{J}$. Zool. 184: 403-419.

Struhsaker, T. T. 1998. A biologists perspective on the role of sustainable harvest in conservation. - Conserv. Biol. 12: 930-932.

Swenson, J. E. 1985. Compensatory reproduction in an introduced mountain goat population in the Absaroka Mountains, Montana. - J. Wildl. Manage. 49: 837843.

Swenson, J. E., Sandegren, F., Söderberg, A. et al. 1997. Infanticide caused by hunting of male bears. - Nature 386: $450-451$.

Unsworth, J. W., Pac, D. F., White, G. C. and Bartmann, R. M. 1999. Mule deer survival in Colorado, Idaho, and Montana. - J. Wildl. Manage. 63: 315-326.

White, G. C. and Bartmann, R. M.. 1998. Effect of density reduction on overwinter survival of free-ranging mule deer fawns. - J. Wildl. Manage. 62: 214-225.

Williams, B. K. 1997. Logic and science in wildlife biology. J. Wildl. Manage. 61: 1007-1015.

Yodzis, P. 1989. Introduction to theoretical ecology. - Wiley, New York. 